كتاب : Television in the age of Radio

" التليفزيون فى عهد الراديو"

تأليف : Philip Sewell

(USA: Rutgers University Press, 2014)

إعداد: د. الأميرة سماح فرج عبد الفتاح"

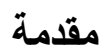

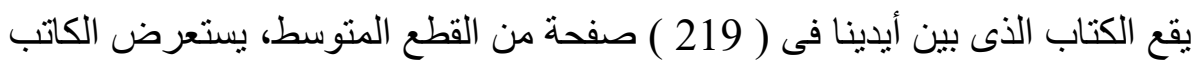

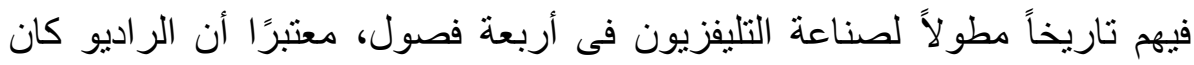

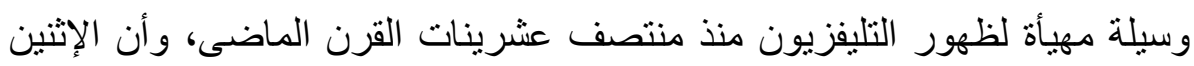

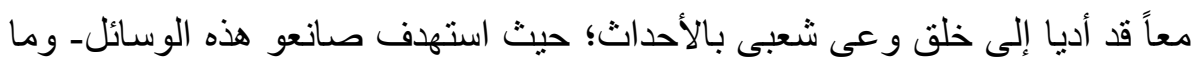

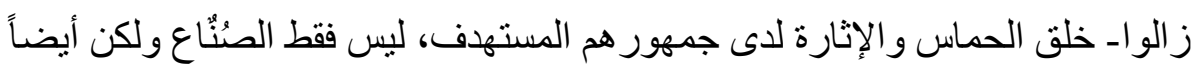

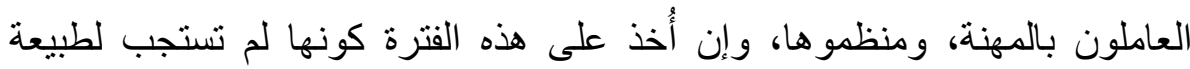

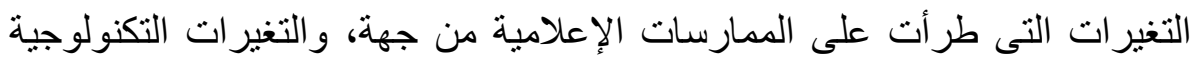

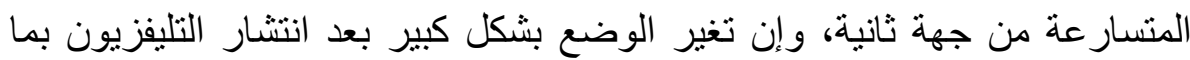
يتنتاسب و النماذج المؤسية المختلفة.

ويدور الكتاب - فى هدفه الأخير - حول إلقاء الضوء على الطريقة التى تتشكل بها

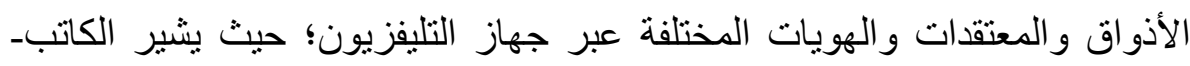
على سبيل المثال- إلى آلية عمل التليفزيون الأمريكى فى توظيفه الأذواق" المرئية

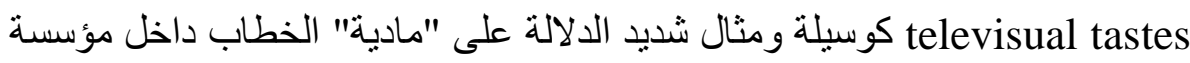

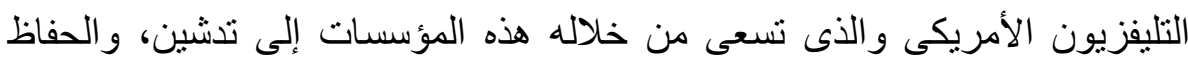

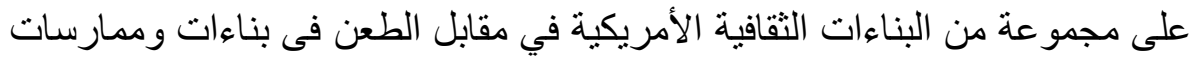
أخرى لتخرج بها عن نطاق المقبول.

* مدرس بقسم الإذاعة والتليفزيون بكلية الإعلام - جامعة القاهرة 


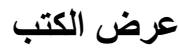

وفى سبيل تحقيق الهدف السابق للكتابـ المعنى برسم خريطة كثفية لطبيعة النظم و المتناقضات فى" أنظمة الذوق التليفزيونى" ـ اعتمد الباحث على تحليل مجموعة

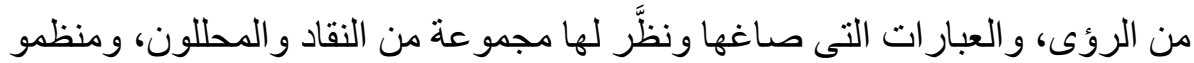
ومشر عو المهنة، ومنفذو ها، ومختر عو ها وحتى نشطاء المشاهدين ممن يبدون أر ائهم فى صناعة التليفزيون.

وقد تمكن المؤلف من جمعها عبر مجموعة الوثائق الحكومية، أرشيف الصناعة) صناعة التليفزيون)، المقالات الأكاديمية، الصحف الشعبية.....إلخ؛ حيث توفر هذه الوثائق مادة خصبة لتقديم رؤى نقدية للنقاثـات و السجالات الدائرة حالياً حول مستقبل

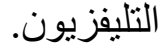

وقد قسمت فصول الكتاب- موضوعاً. لتتناول أولاً ما هو ذى صلة بالتكنولوجيا

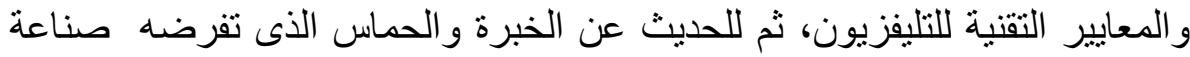
التليفزيون، ثم البناء المؤسسى للوسيلة، وأخيراً طبيعة المضامين التي يقدمها التليفزيون، وطبيعة التأثيرات و القضايا الثقافية التي تثير ها.

و هكذا يستعرض الكاتب فى الفصل الأول للكتاب كيف أن الجدل الدائر حول مسمى "التليفزيون" و استخداماته، ومعاييره التقنية قد رشثَّدت من إدرالك الوسيلة لدى الجمهور كتقنية جديدة بحيث جعلتها جزءاً من ثقافة لابد أن تسود آنذالك وهى ثقافة

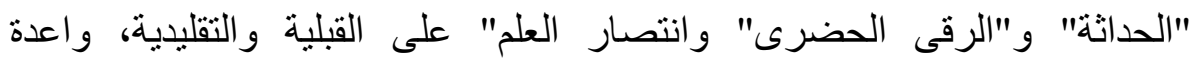
الجماهيربأسطورة" يوتوبيا الوسيلة الكهربائية رفيعة الثنأن" .

ويرسم النصف الأول من الفصل خطوطاً دقيقة للعمليات التى ميزت بعض التطور ات التكنولوجية باعتبار ها فى صميم عملية تطور التليفزيون، فى حين اعتبر البعض منها أطر مشجعة أو مهيأة وداعمة لبروزه على ساحة العمل الإعلامى.

ويظهر الفصل الأول كذللك كيف أن المصالح المتنافسة والمتصارعة فى صناعة التليفزيون قد أثرت على عمليات التأطير الثقافى للمضامين التى يقدمها وفق العرق، 


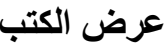

و النوع الاجتماعى وغير ها من الموضوعات الساخنة والمُختلف عليها من أطر اف

وقد شكلت هذه العمليات معاً إدر اكاً جماهيرياً للتليفزيون باعتباره وسيلة تسعى للكمال و المثالية بعيداً عن أية أخطاء محتملة قد تستلزم إعادة التفكير فى الوسيلة وما تحمله

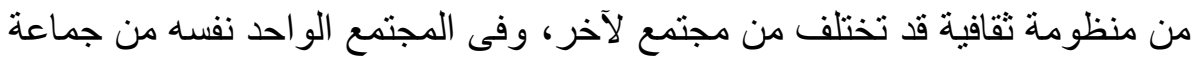

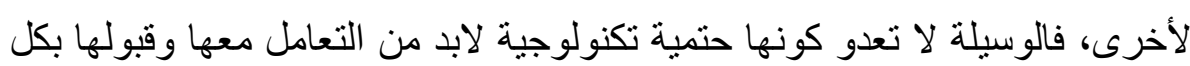

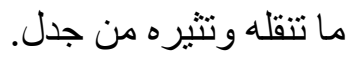

ويحلل الجزء الثانى من الفصل الأول التوجهات المختلفة للجدل الخاص بالتطور التكنولوجى للوسيلة بالتركيز على النظم المعرفية والقوة الصناعية التى تنشد الكمال

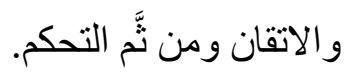
ويختبر الفصل الثانى عمليات " تأطير مدركات" كل من السلطات و الجمهور العام وفق التطورات التكنولوجية التى كان من الحتمى تبينها فى النظام الإعلامى بشكل عام وفى صناعة التليفزيون على وجه الخصوص تاركة مساحة ضئيلة للابداع و الابتكارو التمهل فى صياغة ما يقدم من مضامين، الأمر الذى وضع التليفزيون على وهى

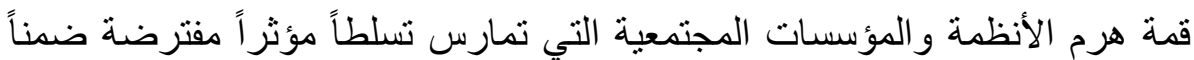
سلبية الجمهور.

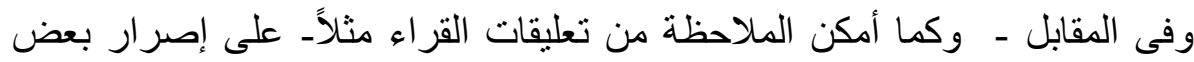
المطبوعات على إجمال تأثيرات التليفزيون على الجمهور دون النظر إلى طبيعة الفروق بينهم، أمكن التوصل إلى وجود العديد من الرؤى البديلة والتصورات الناضجة لدور التلفزيون فى المجتمع آنذاك .

ويعارض هذا الفصل فكرة اتهام الجماهير (أو بالأحرى الجمهور المفتت) بالسلبية و التلقي اللاو اعى للتليفزيون كوسيلة جديدة؛ حيث توصل المؤلف فيه إلى وجود العديد من التوترات التى شابت المراحل الأولى من وجود التليفزيون وهو ما جعل

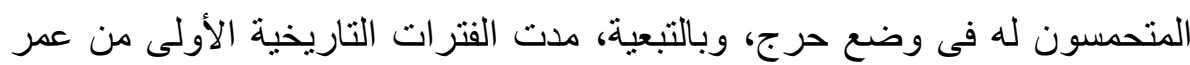




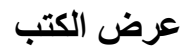

التليفزيون والتى انخرط فيها كل من المتخصصين، والمتحمسين، وحتى الجمهور العادى، مدت الباحثين برؤى كثيرة ذات دلالة.

ويشير الفصل الثالث من الكتاب إلى أن اسلوب بناء الخطاب لنوعيات البرامج التى بدأت مع بداية الإذاعة كوسيلة صوتية قد استخدت من قبل منظمى الوسيلة و الإذاعيين آنذاك لتبرير وتمرير النزعة التجارية نفسها والأساليب التنظيمية الر أسمالية للتليفزيون باعتباره وسيلة جماهيرية أو شعبية.

ويؤكد الفصل مرة أخرى على الفكرة نفسها بالقول إنه حتى نماذج التجارة Business models وقتها قد كرست للفكرة نفسها التى جعلت الوسيلة أسلوباً وأداة من أدوات الر أسمالية والانتاج المركزى و التوزيع الاحتكارى حتى أنها ربطت التنوع

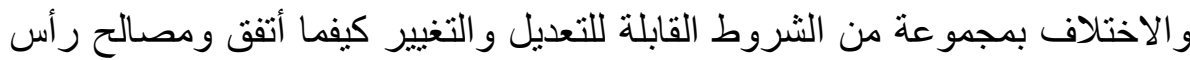

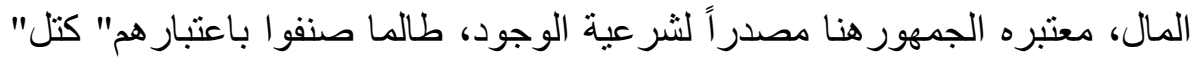

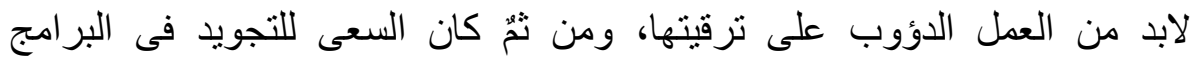
التليفزيونية ما هو إلا لمزيد من التكريس والتفاقم لمشكلة الحشد الثقافى التى كان الراديو يعانى منها بالفعل وهو ما جعل نموذج" الاستقرار الثقافى" هو النموذج هن

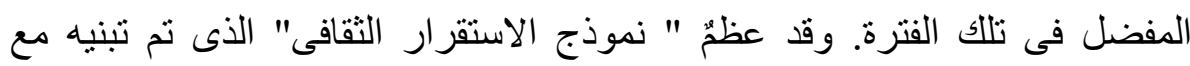

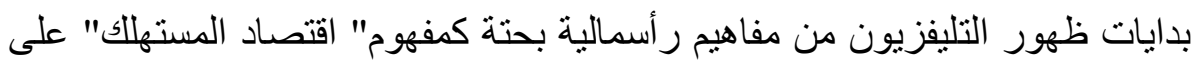

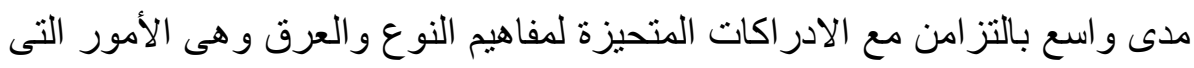
سهلتـ مجتمعة ـ- مرور الرسائل التي تثير التوترات والمتحيز ات المختلفة للمنازل جاذبة معها الجمهور لعالم السوق.

وفى محاولة لاستمالة الجمهور المحتمل وتوقع التغيرات فى الجوانب التجارية

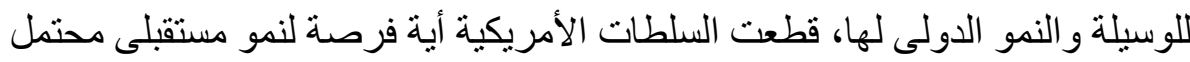

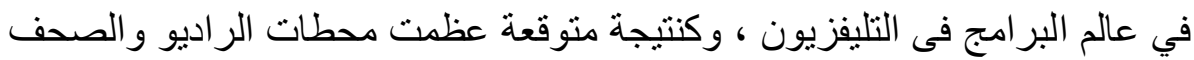

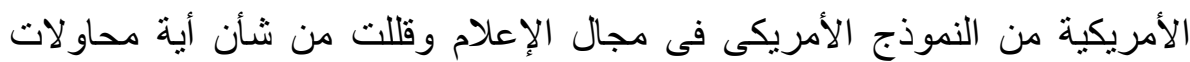
أوربية لتجربة التليفزيون وقدر اته المختلفة. 


\section{عرض الكتب}

ويُختتم هذا الفصل بتحليل للتبعات الثقافية المختلفة التى ترنبت على هذه التوجهات ممهذة لمناقتة أعمق لهذه الأفكار فى الفصل الرابع والأخيرمن الكتاب، والتى بدأها

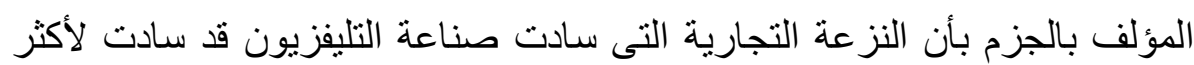

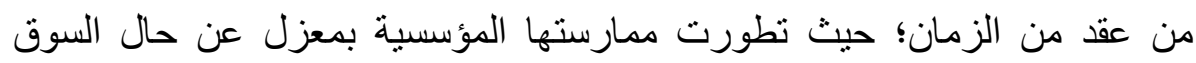
الحقيقية، وبمعزل عن الاختبار و الاقتر اب الفاحص و الدقيق للأحو ال الفعلية للجمهور

و هكذا يتحول الفصل الرابع والأخير من الكتاب للمفاهيم المرتبطة بطبيعة التليفزيون فى علاقته بجمهوره المتوقع فى فترة احتجابه فعلياً عن هذا الجمهور. ويشير المؤلف إلى أن تلك التصورات عن الجمهور جاءت نتاجاً لتدفق ضخم ومتنوع

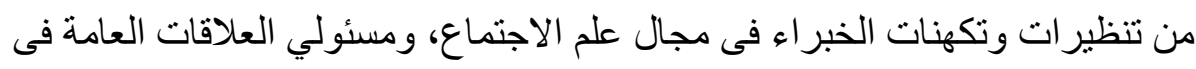
الثركات المختلفة، والمتحمسين من جماعات المصالح، فضلاً عن هؤلاء المتهمين بالجدل الدائر حول التليفزيون من العاملين فى المهنة أنفسهر. ألقت تلك التصورات بظلالها وبثدة على النظام الإعلامى والممارسات وصناعة البرمجة التى سادت فى فترة ما بعد الحرب العالمية الثانية. ويؤكد المؤلف أن هذه العلاقة الثائكة بين التليفزيون وجماهيريه قد شهدت نوعاً من

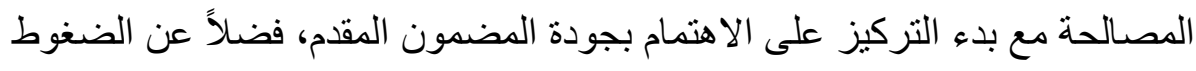
المجتمعية التى حتمت ضرورة كون العلاقة بين الوسيلة وجمهور ها علاقة تبادلية. و هكذا يثير المؤلف فى نهاية كتابه إلى أن فصول الكتاب قد حاولت مجتمعة تقديم فهماً موضوعياً للتلبفزيون من خلال الوقوف على فلى الحتميات التاريخية التى شكلت أسس هامة للجدل الدائر حتى الآن حوله كوسيلة على الرغم من السعى الظاهر نحو

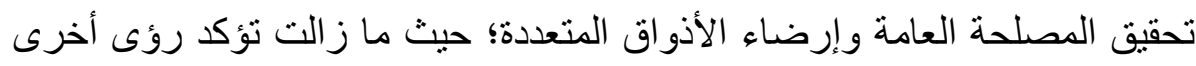
كثثرة أن هذه المظاهر لاتعنى شئ سوى تحقيق مصالح القوى المؤسسية المهيمنة

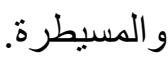


ويختتم المؤلف كتابه قائلاً "إذا كان النموذج التاريخى للتليفزيون كوسيلة إعلامية، قد

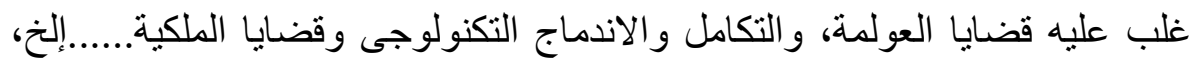

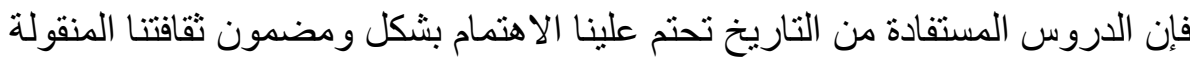
عبر هذه الوسيلة، والتى يناط بها فى كثير من الأحيان ترجمة وإعادة تثكيل المخيلة

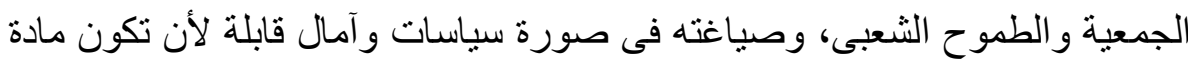
خصبة ضاغطة ودافعة وقابلة للنحقق" . 